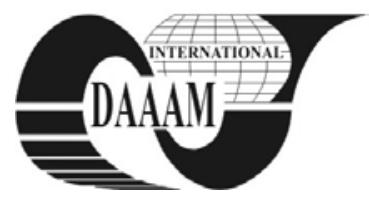

\title{
EXPERIMENTAL ASSESSMENT OF DYNAMIC EFFICIENCY OF SPIROID GEARS
}

\author{
RIECICIAROVA, E[va] \& ORAVCOVA, J[armila]
}

\begin{abstract}
The efficiency of spiroid gear was meassured on the experimental stand in dependence on the set of independent input variables, consisting from such items as the time or position function of the driving moment and the type of the loading. Material combinations ranging from the conventional steel-bronze to more exotic pairs of steel-plastics with different lubricants have been used to evaluate the efficiency of spiroid gears as the function of the applied torque.
\end{abstract}

Key words: spiroid gears, mechanical efficiency, experimental determination

\section{INTRODUCTION}

In Fig. 1 is shown scheme of the dynamic dynamometer, which allows to measure dynamic properties of the machine aggregates and also to control their behaviour. The testing equipment allows application of active and also passive dynamic loading.

Experimental equipment for dynamic loading of the machine aggregates makes possible to monitor influence of the aggregate parameters on irregularity of rotation speed $\omega(t)$ and driving torque $M(t)$ in respect of time or to obtain dynamic features of the machine aggregates within its stabilized and transitional condition in form $M_{z}(\omega)$ given by expression (1). It makes possible to consider suitability machine with regard to its reliability in operation, accuracy and efficiency within various loading forms (Mudrik \& Nanasi 2008).

The gearbox with spiroid gearing (Fig. 2) was tested as a component of the machine aggregates containing a drive and loading machine.

The spiroid gearing is an intermediate gearing type between hypoid and worm gearing pertaining to gearing group with skew line axes. It consists of spiroid worm with its cylindrical or cone shape and spiroid disk gear with teeth of arc shape. In comparison with the worm gearings, the spiroid gearings feature by smaller slips of the meshing gear surfaces, further by better conditions for formation of liquid friction and more favourable spreading of contact lines. Fundamental difference between classical and spiroid worms lies in profile asymmetry of the spiroid worm (Oravcova 2006).

The goal of this contribution is to complete information on field of the spiroid gear static loading and of torque size

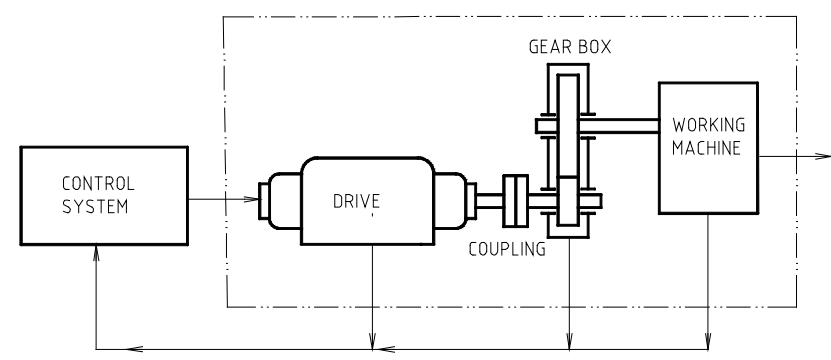

Fig. 1. Scheme of dynamic stend

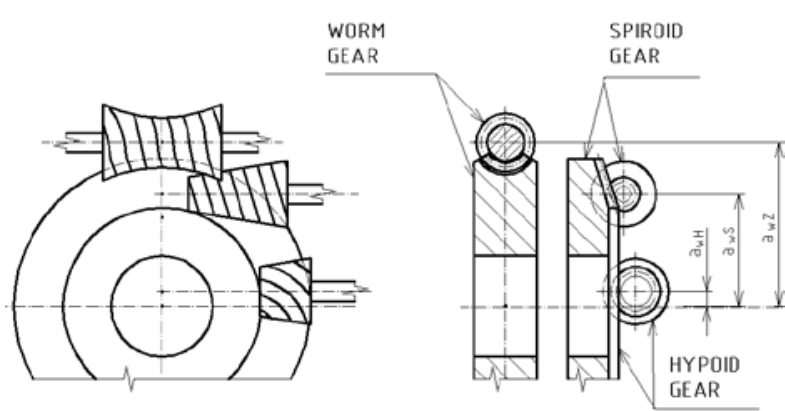

Fig. 2. Type of gears assemblage

influence on its efficiency within formation of various type of friction, measured by dynamical dynamometer.

\section{EXPERIMENTAL MEASUREMENT}

The experimental measurements have been carried out using the dynamical stend, which allowed to follow influence of the aggregate parameters on irregularity of angular velocity $\omega(t)$ and driving moment $M(t)$ or to obtain dynamical characteristic of the machine aggregate in its stable and passage state in the form $M(\omega)$. It makes possible to assess machine suitability with regard to its operational reliability, accuracy and its performance within various loading effects (Oravcova 2006).

An asynchronous motor (under frequency control) drove the tested gearbox. On the gearbox output side was located direct-current motor and controlled rectifier working in inverted mode. Current controller controls the rectifier when on the controller input is located generator of elective formed control voltage. Its form corresponds with shape of the transmission mechanism loading torque.

Contemporary discrete programmable control makes possible to improve pre-project documentation by means of the dynamical experimental simulations using mathematic-physical model. By the same way can be also improved testing quality. The dynamical experiments utilising the new generation dynamometers are new testing elements. The dynamical stend makes possible confrontation of the measured results with the results obtained by means of CAMS.

In the experiment the gear box with spiroid gear was tested. The spiroid gear was assembled using spiroid worm of cylindrical shape and spiroid disc with teeth of arc shape. Parameters of the spiroid gear box:

- gearing modulus $m=1,75 \mathrm{~mm}$,

- gear ration $i=1: 49$,

a) spiroid worm:

- material - steel 12060.4 (C 55 E),

- number of teeth: 1

b) spiroid disc:

- material - bronze Cu Al8 Fe3 (Fig.5), - murlubric (Fig.6), 
• number of teeth: 49

\subsection{Spiroid gear by steel - synthetic material}

In the first measuring set was efficiency by spiroid gear steel - murlubric determined. Static loading driving moment $M_{\mathrm{z}}(\omega)$ by constant angular velocity $n_{d}=1000 \mathrm{~min}^{-1}$, was used in this load state. Parameters of equation (1) used for set-up driving moment in the equipment control system are summarized. Value of static driving moment used in control system is calculated by equation:

$$
M_{z}(\omega)=K_{-1} \omega^{-1}+K_{0} \omega^{0}+K_{1} \omega^{1}+K_{2} \omega^{2},
$$

where: $K_{-1}, K_{0}, K_{1}$ a $K_{2}$ are constants,

$\omega$ is angular velocity,

$x$ is given by list $\langle-1 ; 0 ; 1 ; 2\rangle$.

By exponent $x$ in equation (1) is possible to assume different standard loading characteristics. Losses of mechanism in stationary state run are characterized by efficiency coefficient $\eta$. Gear efficiency is defined by portion of output power to input power (2):

$$
\eta=\frac{M_{k a} \omega_{k a}}{M_{k j} \omega_{k j}},
$$

where: $M_{k a}$ means output torque,

$\omega_{k a}$ means output angular speed

$M_{k j}$ means input torque,

$\omega_{k j}$ means input angular speed.

In the Fig. 3 can be found the measured and calculated values connected with spiroid gearing. The measurements have been carried out with dry friction, further with oil friction using the lubrication means type: MADIT OT-HP 32 and MADIT PP 80.The testing equipment has the limited torque value from 30 up to $50 \mathrm{Nm}$ what allows measuring the transmission intended only for small loading torques directly.

\subsection{Spiroid gears by steel - bronze}

In the second measurements set was efficiency of spiroid gearing combination steel - bronze determined (Fig. 4). Mean value of loading torque $M_{\mathrm{z}}(\omega)$ by constant angular velocity $n_{d}=1000 \mathrm{~min}^{-1}$, was used in this load state (Nad 2007).

\section{CONCLUSION}

Utilization of the testing equipment for dynamical loading of the machine aggregates and mechanisms can be used for creation of dynamic loads with defined static and dynamic parameters within a technological process (Mudrik \& Nad 2007).

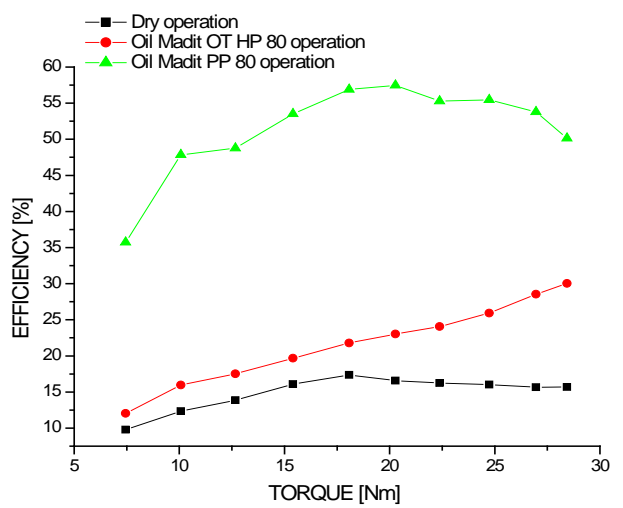

Fig. 3. The influence of static loading on the efficiency of spiroid gear steel - murlubric

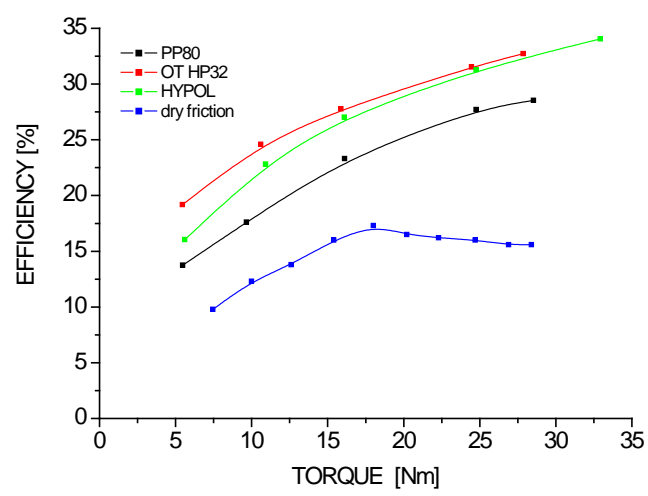

Fig. 4. The influence of static loading on the efficiency of spiroid gear steel - bronze

Further the said equipment can be utilised for laboratory, production and input tests and for service life tests of any subsystem of a mechatronical systems under given dynamic loads.

The goal of this contribution is to bring closer the problematic of static load influence on the spiroid gears and influence of torque value on gear efficiency within creation of various type of friction, when carrying out measurements using dynamical dynamometer. The tested single-stage gearbox is the gearbox with gear ratio $\mathrm{i}=49$ and gearing module $\mathrm{m}=1,75$ $\mathrm{mm}$, when pinion material is steel and gear wheel is made of bronze. It has been found out from the measured and calculated values that the lowest efficiency is within dry friction run. Influence of loading increase, i.e. of torque increase is the increase of gear efficiency, which increases up to its maximum value reached. Being the maximum efficiency reached, the efficiency is decreasing while the further loading still increases.

The measurement results show on gear efficiency dependence on teeth surface temperature. With temperature raising the efficiency decreases.

\section{ACKNOWLEDGEMENTS}

The results and such way also the contribution came into existence in connection with MŠ SR grant support of the project VEGA - 1/0389/11.

\section{REFERENCES}

Mudrik, Jozef - Nánási, Tibor: Principles of Mechatronical Modelling of Machine Aggregates. In Annals of DAAAM and Proceedings of DAAAM Symposium. "Intelligent Manufacturing \& Automation: Focus on Next Generation of Intelligent Systems and Solutions", 2008, Trnava, Slovakia. - Viedeň: DAAAM International Vienna, 2008. ISBN 978-3-901509-68-1, p. 0917-09181)

Oravcová, Jarmila: Analysis of influence kinematic inaccuracy of spiroidal gear in machine aggregate. In CO-MAT-TECH 2006. 14. International scientific conference, Bratislava: STU, 2006. p. 939-942

Oravcová, Jarmila: Spiroid gears and theirs kinematic inaccuracies.In CO-MAT-TECH 2005, Proceedings/ International Scientific Conference, 13th, Trnava, Slovak Republic, STU v Bratislave, 2005. - ISBN 80-227-2286-3. S. $878-881$

Nad', M.: Moving belt resonant properties of drive systems. In: Acta Mechanica Slovaca, Vol.. 11, č. 4-A/2007, pp. 143150, ISSN 1335-2393

Mudrik, J. - Nad', M.: Mechatronical approach to machine dynamics. In: Proceedings of $10^{\text {th }}$ International Symposium on Mechatronics - „Mechatronika 2007“, Trenčianske Teplice, Trenčianska univerzita Alexandra Dubčeka v Trenčíne, 2007, pp. 33-38, ISBN 978-80-8075-210-1 